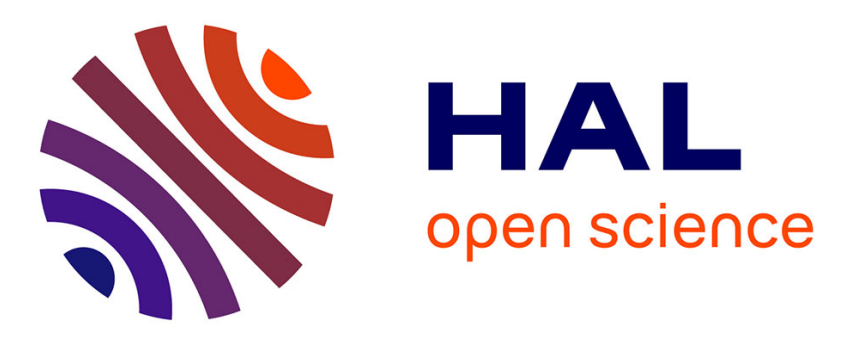

\title{
Advanced three dimensional characterization of silica-based ultraporous materials
}

Genevieve Foray, Lucian Roiban, Q. Rong, A. Perret, D. Ihiawakrim, Karine Masenelli-Varlot, E. Maire, B. Yrieix

\section{- To cite this version:}

Genevieve Foray, Lucian Roiban, Q. Rong, A. Perret, D. Ihiawakrim, et al.. Advanced three dimensional characterization of silica-based ultraporous materials. RSC Advances, 2016, 6 (13), pp.1062510632. 10.1039/c5ra26014k . hal-01674655

\section{HAL Id: hal-01674655 \\ https://hal.science/hal-01674655}

Submitted on 3 Jan 2018

HAL is a multi-disciplinary open access archive for the deposit and dissemination of scientific research documents, whether they are published or not. The documents may come from teaching and research institutions in France or abroad, or from public or private research centers.
L'archive ouverte pluridisciplinaire HAL, est destinée au dépôt et à la diffusion de documents scientifiques de niveau recherche, publiés ou non, émanant des établissements d'enseignement et de recherche français ou étrangers, des laboratoires publics ou privés. 


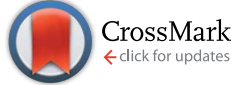

Cite this: RSC Adv., 2016, 6, 10625
Received 6th December 2015 Accepted 15th January 2016

DOI: 10.1039/c5ra26014k

www.rsc.org/advances

\section{Advanced three dimensional characterization of silica-based ultraporous materials $\uparrow$}

\author{
L. Roiban, ${ }^{\star a}$ G. Foray, ${ }^{\star a}$ Q. Rong, ${ }^{a}$ A. Perret, ${ }^{a b}$ D. Ihiawakrim, ${ }^{c}$ K. Masenelli-Varlot, ${ }^{a}$ \\ E. Maire ${ }^{a}$ and B. Yrieix ${ }^{b}$
}

Whatever the field of application (building, transportation, packaging, etc.) energy losses must be reduced to meet the government target of a $40 \%$ cut in $\mathrm{CO}_{2}$ emissions. This leads to a challenge for materials scientists: designing materials with thermal conductivities lower than $0.015 \mathrm{~W} \mathrm{~m}^{-1} \mathrm{~K}^{-1}$ under ambient conditions. Such a low value requires reducing air molecule mobility in highly porous materials, and silica-based superinsulation materials (SIM) made of packed nanostructured silica or aerogel are good candidates for this purpose. However, the native nanostructure of silica has never been imaged or characterized up to now, making SIM optimization quite difficult. In this paper, three nanostructured commercial silica samples prepared by different synthesis methods were analysed and quantified using advanced electron tomography, $\mathrm{N}_{2}$ physisorption, mercury porosimetry and helium pycnometry. It was demonstrated that 3D images yield a much finer description of the microstructure (particle, aggregate and pore) compared to global measurements. For the samples studied, silica particle size is dependent on the synthesis method, increasing with pore diameter size. The smallest silica particles were obtained by the sol-gel method which also provides the smallest pore diameters, the smallest and rather spherical aggregates, and the lowest thermal conductivity. The pyrogenic and precipitated samples studied presented bigger silica particles with higher pore diameters and thus higher thermal conductivities. 3D image driven characterization opens up new synthesis opportunities for silica.

\section{Introduction}

Global warming and climate change ${ }^{1}$ due to the combustion of fossil fuels are global issues. The accepted political solution is to decrease $\mathrm{CO}_{2}$ emissions in the atmosphere in future decades. $^{2}$ Presently, our needs for transportation, power plants, food delivery, heat, heavy industry, technology and buildings are closely dependent on oil, gas and coal consumption. ${ }^{3,4}$ Since the $1970 \mathrm{~s}$, legal restrictions have constrained heavy industry, including the building industry, to abate greenhouse gas emissions and develop new environmentally friendly technologies. Breakthroughs are demanded regarding insulation in buildings, cars, refrigerators, pipes, etc. ${ }^{5}$

The best energy is that which is not consumed and buildings are the world's leading source of energy saving. Much effort is being focused on thermal insulation when renovating

${ }^{a}$ Université de Lyon, INSA-Lyon, Université Claude Bernard Lyon 1, CNRS UMR-5510, MATEIS, 7, Avenue Jean Capelle, 69621 Villeurbanne Cedex, France. E-mail: lucian. roiban@insa-lyon.fr; genevieve.foray@insa-lyon.fr

${ }^{b} E D F R \& D, M M C$, Avenue des Renardières - Ecuelles, 77818 Moret sur Loing Cedex, France

'Institut de Physique et Chimie de Matériaux (IPCMS), CNRS-UMR 7504, Université de Strasbourg, 23 rue du Loess, BP 43, 67034 Strasbourg Cedex 2, France

$\dagger$ Electronic supplementary information (ESI) available. See DOI: 10.1039/c5ra26014k buildings, to reduce the energy lost through the structure as much as possible. Several solutions are currently proposed, such as adding a thicker layer of a classical material on the walls, or a multilayer product including insulating materials. Because a large thickness is required to reach a sufficiently high thermal resistance, these systems lead to either complex façades in the case of external insulation, or to a considerable loss of habitable space in the case of internal insulation. To overcome these issues, the main goal is to reduce the intrinsic thermal conductivity of the insulating layer to reach higher thermal resistance with lower thickness. Under stationary conditions thermal conductivity is the fundamental property governing the heat exchange between two opposite sides of a material with a given thickness under a given temperature gradient. ${ }^{3}$ In the case of porous materials, such as silica aerogels or packed nanosilica, the conductivity of a segment is considered as the sum of the solid skeleton conductivity, the gas conductivity and the radiative conductivity. As gas is confined in pores whose diameters are close to the mean free path or air molecule, the conductivity $\lambda_{\mathrm{g}}$ of the gas is lowered (Knudsen effect $\left.^{6,7}\right) . \lambda_{\mathrm{g}}$ can be expressed as: $\lambda_{\mathrm{g}}=\frac{\lambda_{\mathrm{g} 0}}{1+\alpha \frac{T}{\delta P}}$, where $\lambda_{\mathrm{g} 0}$ represents the thermal conductivity of the gas (air for insulation purposes), $T$ and $P$ correspond to the temperature and the 
pressure of the gas, respectively. $\alpha$ is a specific constant of the gas inside the pores, $\alpha=\frac{\sqrt{2} k \beta}{\pi d_{\mathrm{g}}{ }^{2}}$, with $k$ being the Boltzmann constant, $d_{\mathrm{g}}$ the gas molecule diameter and $\beta$ a constant near $1.5 .^{8}$ Finally, $\delta$ characterizes the pore size within the materials. Mesoporous materials with small $\delta$ values $(2<\delta<50 \mathrm{~nm}$ according to IUPAC definition) are therefore expected to exhibit the lowest thermal conductivities. They are one of the innovative solutions for the synthesis of superinsulation materials (SIM). Granular nanostructured silica exhibits high porosity, low thermal conductivity, low sound velocity and low density. Moreover, it is possible to achieve sustainable mass production at affordable costs. Therefore they are excellent base product candidates for manufacturing efficient/durable thermal superinsulation products ${ }^{9}$ formed by packing nanostructured grains.

Nanostructured silica grains are characterized by their chemical composition, their synthesis method and their commercial form as powder/granular material or monolithic material. ${ }^{10}$ Several methods can be envisaged ${ }^{11}$ to provide high surface areas and ultra-low bulk densities, such as sol-gel, ${ }^{12}$ precipitation $^{\mathbf{1 3 , 1 4}}$ and pyrogen (also called fumed) ${ }^{\mathbf{1 5}}$ by controlling different parameters such as temperature, ${ }^{16}$ pressure,${ }^{17}$ type of solvent, $\mathrm{pH}$ and process parameters, ${ }^{18}$ and by using supercritical drying. ${ }^{19,20}$ Each different route leads to a different type of porous microstructure in the final product. The nature of this microstructure has a strong influence on the final thermal conductivity so it is very important to characterize/control this parameter. As far as porosity characterization is concerned, several complementary techniques are currently used, including nitrogen physisorption, mercury porosimetry, pycnometry, water sorption, small-angle X-ray scattering (SAXS), scanning electron microscopy (SEM), and transmission electron microscopy (TEM). However, the information provided in most cases is volume averaged, restricted to a surface description or limited to a bi-dimensional projection. For highly mesoporous silicas such as those required for SIM applications, the information obtained can also be affected by several artefacts. ${ }^{21-23}$

Several studies performed by X-ray tomography ${ }^{24-26}$ have succeeded in insight into the inter-granular three-dimensional porous network distribution. The upper part of the porosity curve, which is a major contributor to the gas thermal conductivity, has been fully described within samples of a few centimeters; the even 3D distribution of micron size adsorbant particle has been confirmed. The major drawback of this technique lies in the fact that the resolution is limited to a few micrometers using standard tomography, which precludes the characterization of the smallest pores, designed by the synthesis path. But nanometric resolution in three dimensions can be achieved by electron tomography. ${ }^{27-29}$

However, electron tomography requires long acquisition times. Indeed, for each tilt angle, the sample tracking and the sample focus are calculated using a region of interest. The sample can undergo electron irradiation lasting from several minutes to several hours. An overall inexact reconstructed volume will be computed on beam sensitive samples, because of structural changes and the internal motion induced during tilt series acquisition. This might explain the lack of studies performed and published up to now on beam sensitive materials such as aerogels. ${ }^{30}$

In this paper, these difficulties were overcome for the first time by using advanced technology and a specific test protocol: silica beam sensitive samples were fully characterized by electron tomography in so-called advanced mode (AET). 3D imaging and quantitative analysis of the tomograms gave breakthrough information, including elementary particle size, pore network structure, size and connectivity and, last but not least, aggregate morphology. The results are completed with those obtained by classical characterization techniques: conventional TEM, $\mathrm{N}_{2}$ physisorption, $\mathrm{Hg}$ porosimetry, and He pycnometry. These data will provide new opportunities and possibly lead, initially, to optimized silica synthesis and, secondly, to modelling studies to improve SIM properties. This AET protocol would for sure give the opportunity to image other nanostructured materials in the field of superinsulation (such as polymer aerogels, bio-inspired aerogels). Last but not least, it will help in any application requiring antagonism properties where nanoporosity is implied.

\section{Materials}

To demonstrate the possibilities of the advanced technique, three mass production commercial samples of interest for thermal superinsulation were analysed. For the sake of clarity, they were differentiated by their different production processes. Their main properties are shown in Table 1.

The hydrophobized granular silica aerogel, referred to as "Aero Sample", contains an extremely high number of pores (up to $85-90 \%$ of total sample volume). Up to now, based on bidimensional imaging techniques and global measurements, aerogels have been commonly characterized as spherical particles of less than $20 \mathrm{~nm}$ in size, forming aggregates and agglomerates. These agglomerates are organized in the form of macroscopic grains resembling "local monoliths". Sol-gel synthesis starts with a hydrolyzed precursor and then includes the classical acid/basic process, a hydrophobic treatment with a molecule that replaces half of the surface hydroxyl groups. ${ }^{13}$ The process ends with an ambient pressure drying step, and gentle sieving to separate the product into different commercial grades (ISO GEL produced by ENERSENS).

The synthesis of pyrogenic silica, referred to as "Fumed sample", first relies on an acidic silica dissolution step after

Table 1 General characteristics of the granular nanostructured silica samples, provided by the suppliers

\begin{tabular}{|c|c|c|c|}
\hline Sample & Process & $\begin{array}{l}\text { Reactant and } \\
\text { properties }\end{array}$ & $\begin{array}{l}\text { Specific surface } \\
\text { area }\end{array}$ \\
\hline Aero sample & Sol gel & $\begin{array}{l}\text { TEOS - methyl highly } \\
\text { hydrophobic }\end{array}$ & $900 \pm 50 \mathrm{~m}^{2} \mathrm{~g}^{-1}$ \\
\hline Fumed sample & Fumed & $\begin{array}{l}\mathrm{SiCl}_{4\left[1000-1100^{\circ} \mathrm{C}\right]} \\
\text { hydrophobic }\end{array}$ & $200 \pm 25 \mathrm{~m}^{2} \mathrm{~g}^{-1}$ \\
\hline Prec. sample & Precipitated & $\begin{array}{l}\mathrm{Na}_{2} \mathrm{SiO}_{3} \text { hydrophilic } \\
\text { silanols }\end{array}$ & $220 \pm 25 \mathrm{~m}^{2} \mathrm{~g}^{-1}$ \\
\hline
\end{tabular}


which the suspension is sprayed in a high temperature flame. After the nucleation step, ballistic polymerization occurs followed by sintering and diffusion-limited aggregation. The aggregates are chain-like with a particle size less than $50 \mathrm{~nm}$, and a whole typical size of $200 \mathrm{~nm}$. They form agglomerates that finally provide a micrometric commercial powder. ${ }^{31}$

The precipitated nanostructured silica, referred to as "Prec. Sample", is composed of aggregates of less than $200 \mathrm{~nm}$ in size. As in the two previous cases (Aero and Fumed), the particles tend to form aggregates and then agglomerates. Precipitated silica synthesis starts by silica dissolution in an acidic medium and after precipitation a silica cake is obtained, that is subsequently washed and gently air dried.

\section{Experimental techniques}

Before performing the nitrogen sorption and porosimetry measurements, the silica samples were degassed for 4 hours under primary vacuum at $6.66 \mathrm{~Pa}$ and $140{ }^{\circ} \mathrm{C}$.

\section{Conventional techniques}

Nitrogen sorption measurements were performed with an ASAP Belsorp Max, using nitrogen as absorber. A Brunauer-EmmettTeller (BET) ${ }^{32}$ procedure was used to determine the specific surface area, while a Barrett, Joyner, Halenda $(\mathrm{BJH})^{33}$ calculation gave initial insight into the pore diameter size distribution. The size and content of these materials are possibly underestimated for size within the $3-40 \mathrm{~nm}$ range, due to capillary shrinkage occurring within the sample during the analysis. This artefact increases for larger sizes. ${ }^{21}$ Mercury porosimetry was performed with a Micromeretics Autopore III. Data was obtained from 80 measurement points, while the sample was subjected to increasing pressure from 0.001 to $413 \mathrm{MPa}$ in order to augment the overall pore volume by intrusion or skeleton collapse, and from 30 further measurements points while the pressure was decreased from 400 to $0.1 \mathrm{MPa}$ to obtain information on pore network tortuosity. Once the target pressure was reached, the measurements were performed after a 20 s stabilization step. Powder measurement cells with a $5.913 \mathrm{ml}$ cell volume and $1.131 \mathrm{ml}$ capillary stem volume ensured the best reproducibility on three replicates. Pirard developed a specific procedure to analyse mixed behaviour mechanical collapse and intrusion, and proved that some ultraporous aerogels are not fully characterized by this method. ${ }^{34}$ The work done by Guerin ${ }^{35}$ led to a specific method for quantifying mesopore volume due to mechanical collapse only and proposed an innovative method for characterizing powder processability through a mercury porosimetry test. Using both methods, here we focused only on mesopores [2-50 $\mathrm{nm}]$ ([20 $413 \mathrm{MPa}])$ as defined by the IUPAC standard. Helium pycnometry was performed on a Micromeretics Accupyc 1330 apparatus; the measured value was the average value over twenty cycles. Bulk density was measured by filling a vessel of known volume with silica powder without compaction. ${ }^{36}$

\section{Advanced technique}

The transmission electron microscopy (TEM) observations were performed on a Jeol 2010F TEM equipped with a field emission gun (FEG) and a Gatan Ultrascan CCD camera. The powder samples were dry deposited on a microscopy grid previously prepared for electron tomography by depositing a droplet of a suspension containing colloidal gold nanoparticles $(5 \mathrm{~nm}$ in diameter). The role of these markers was to improve projection alignment. The tilt series were recorded automatically, using the GATAN tomography software in the low dose bright field mode. Each tilt series was recorded within an angular range starting from $-71^{\circ}$ to $+71^{\circ}$ with an increment following a Saxton scheme $^{37}$ (tilt step at $0^{\circ}$ equal to $2.5^{\circ}$ ). The total acquisition time was about 45 minutes, resulting in 81 images of $2048 \times 2048$ pixels with a pixel size of about $0.16 \mathrm{~nm}$ for the Aero Sample and $0.2 \mathrm{~nm}$ for the Fumed and Prec. samples. In this study, we developed an innovative method referred to as "advanced mode" electron tomography. The advantage provided by AET compared to the classical tilt series acquisition in electron tomography consists in the auto-focalisation and the autotracking of the samples using cross correlation. This is performed automatically on a region different from the region of interest, which prevents any sample beam damage. The area of interest is thus exposed exclusively during image acquisition, here during 0.5 second only for every projection. The resulting projections recorded allowed us to perform a three dimensional (3D) analysis even in the case of beam sensitive samples. The projection of the sample was observed before and after the tilt series acquisition to confirm the zero damage detection hypothesis. After the tilt series acquisition, a rigorous alignment was applied employing IMOD software ${ }^{38}$ using the Au nanoparticles as fiducial markers. The $512 \times 512 \times 512$ volume computations were performed using the algebraic reconstruction technique algorithm (ART) ${ }^{39}$ implemented in TOMOJ/ EFTETJ software ${ }^{\mathbf{4 0}}$ with 15 iterations. The 3D visualization, surface rendering, pore sizes and silica particle quantification were performed combining different tools implemented in the sharewares Image J, ${ }^{41}$ 3D Slicer ${ }^{\mathbf{4 2}}$ and Chimera. ${ }^{\mathbf{4 3}}$ As this material study clearly dealt with nanoscale texture (i.e. particles within a 2-30 nm range), the volume imaged was kept ten times higher than the primary object studied, around $300^{3} \mathrm{~nm}^{3}$.

\section{Results and discussions}

For the sake of clarity, the commercial products analyzed here are referred to in the text sorted by their production type.

\section{Conventional techniques}

The bulk analyses provided by $\mathrm{N}_{2}$ physisorption, $\mathrm{Hg}$ porosimetry of the silica samples and thermal conductivity measured on packed material are shown in Table 2. This shows that the thermal conductivities of the materials are different: increasing from the Aero sample to the Prec. sample. The specific surface, obtained from the BET measurements, is the highest for the Aero sample, with $565 \mathrm{~m}^{2} \mathrm{~g}^{-1}$, decreasing to $192 \mathrm{~m}^{2} \mathrm{~g}^{-1}$ for the Fumed samples and to $165 \mathrm{~m}^{2} \mathrm{~g}^{-1}$ for the Prec. sample. The BJH main pore size increases from $15 \mathrm{~nm}$ for the Aero sample to around $40 \mathrm{~nm}$ for the Fumed and Prec. samples. Distribution curves are shown in ESI S1. $\dagger$ 
Table 2 Thermal conductivity, bulk density, ${ }^{36}$ specific surface, main pore size distribution, porous volume, skeleton density and bulk density of the samples

\begin{tabular}{lllllr}
\hline Samples & $\begin{array}{l}\text { Product density/thermal } \\
\text { conductivity } \mathrm{kg} \mathrm{m}^{-3} / \mathrm{mW} \mathrm{m}^{-1} \mathrm{~K}^{-1}\end{array}$ & $\begin{array}{l}\text { Specific surface } \\
\left(\mathrm{m}^{2} \mathrm{~g}^{-1}\right)\end{array}$ & $\begin{array}{l}\text { Pore size BJH } \\
(\mathrm{nm})\end{array}$ & $\begin{array}{l}\text { Pore vol. Hg } \\
\text { meso UPAC }\left(\mathrm{cm}^{3} \mathrm{~g}^{-1}\right)\end{array}$ & $\begin{array}{l}\text { Skeleton density } \\
\left(\mathrm{kg} \mathrm{m}^{-3}\right)\end{array}$ \\
\hline Aero sample & $133-16.2^{a}$ & 565 & $7 \pm 1$ & 0.864 & 1610 \\
$\left(\mathrm{~kg} \mathrm{~m}^{-3}\right)$
\end{tabular}

The total porosity measurement was beyond the detection limit for $\mathrm{Hg}$ porosimetry whatever the powder sample, however computations from densities indicated that it was highest for the Fumed sample. Surprisingly, the smallest mesopore volume, of interest for insulation applications, detected by $\mathrm{Hg}$ porosimetry was measured for the Aero sample. Complementary measurements performed with this technique (see ESI S2 $\dagger$ ) indicated that this volume resulted from mechanical compaction for the Aero sample, but was due to compaction and mercury intrusion for the Fumed and Prec. samples. Moreover incremental programs indicated that the aerogel successfully provided a high content of small-sized pores $(7 \mathrm{~nm}$ or less at a pressure close to $400 \mathrm{MPa}$, together with a low content of medium size pores (20 and $30 \mathrm{~nm}$ ). The cumulative detected pore volume measurements confirmed that the Fumed sample had the highest macropore volume while the Aero sample had the highest compaction capacity. ${ }^{35}$

The skeleton density, ratio of mass over particle volume, was measured by He pycnometry. The Aero sample had the lowest skeleton density due to the inclusion of trimethyl hydrophobant groups at the surface of the silica particles. The Fumed and Prec. samples presented almost equal skeleton density values. Bulk density provided initial insight into powder filling capacity, as it represented the powder weight necessary to fill a unit volume under gravity. Regarding the comparison of bulk densities, the Aero sample was the heaviest with a density of 105 $\mathrm{kg} \mathrm{m}^{-3}$, followed by the Prec. and Fumed samples with densities of $90 \mathrm{~kg} \mathrm{~m}^{-3}$ and $40 \mathrm{~kg} \mathrm{~m}^{-3}$, respectively, suggesting that either the particle form factor or hydrophobized silica aggregate network induced specific rheological behavior. ${ }^{45}$ The Aero sample, which had the lightest skeleton material, had the highest bulk density.

The TEM images are displayed as projections in bright field mode. In this display mode, a complex structure is revealed with a heterogeneous porosity (Fig. 1). Indeed, small pores are present between silica nanorods (defined as the smallest particle identified by TEM), whereas bigger pores can be found within the agglomerates and between the aggregates.

Unfortunately, no reliable measurement of the pore size could be performed from such projection images, as it is rather difficult to define cells in the projections. Nevertheless, it seems apparent that the silica frame is composed of a huge number of nanorods, which may be qualified by specialists as the aging and ripening of two or more native spherical silica particles. However their size is obviously sample-dependent. Further investigations are required with more than one sample per process to link size and morphology to the synthesis parameters. The nanorod dimensions are measured roughly as equal to $5 \mathrm{~nm} \times 3 \mathrm{~nm}, 20 \mathrm{~nm} \times 10 \mathrm{~nm}$ and $33 \mathrm{~nm} \times 15 \mathrm{~nm}$ for the Aero, Fumed and Prec. samples, respectively (Fig. 1).

\section{Advanced technique}

A more complete description of the pores could be obtained after $3 \mathrm{D}$ reconstruction via AET. The projection tilt series were recorded using the low dose mode to prevent beam damage as can be seen in ESI, S3. $\dagger$ The reconstructed volume contains a high enough signal to noise ratio to enable the analyses of different reconstructed slices at any depth and any orientation, as shown in ESI S4. $\dagger$ A bimodal pore distribution was observed, with smaller pores between the silica particles and bigger pores inside the aggregates. The 3D models obtained after data segmentation are shown in Fig. 2.

The three dimensional models provided by AET indicate at first glance that the Aero sample produced rather large and dense spherical aggregates while the Fumed and Prec. samples formed small cluster like aggregates with some suspended loose arms. As the adequate aggregate form factor for silica aggregates $^{\mathbf{8}}$ is a well-known keystone for achieving high product compactness, such qualitative AET information is of great value.

AET provided the first direct local quantification data, without any need to rely on a physical model to link pressure or sorption to size. As expected, the results given in Table 3 show a pore diameter distribution where width increases with silica grain size (Fig. 2(e)). The smallest pore diameter is obtained with the Aero sample, while the largest distribution was obtained with the Prec. sample. Indeed in the Aero sample, the size of the pores formed between the silica nanorods ranges from 3 to $10 \mathrm{~nm}$ and those formed between the nanorod assemblies could reach $30 \mathrm{~nm}$. On the contrary, for the Prec. sample, which exhibited bigger nanorods, wider pore sizes can be observed, starting at $5 \mathrm{~nm}$, between the nanorods and increasing to $60 \mathrm{~nm}$ between the nanorod assemblies.

The Fumed sample presents intermediate sized nanorods and thus intermediate pore size distribution. The pore size distribution contains pores as small as $5 \mathrm{~nm}$ in size - pores formed between the nanorods - and ranging to $45 \mathrm{~nm}$ for the pores formed between aggregates. The growth of the pore size distribution with the silica particles size was also confirmed by the BET analyses ( $\mathrm{N}_{2}$ physisorption) and by $\mathrm{Hg}$ porosimetry. 
a)

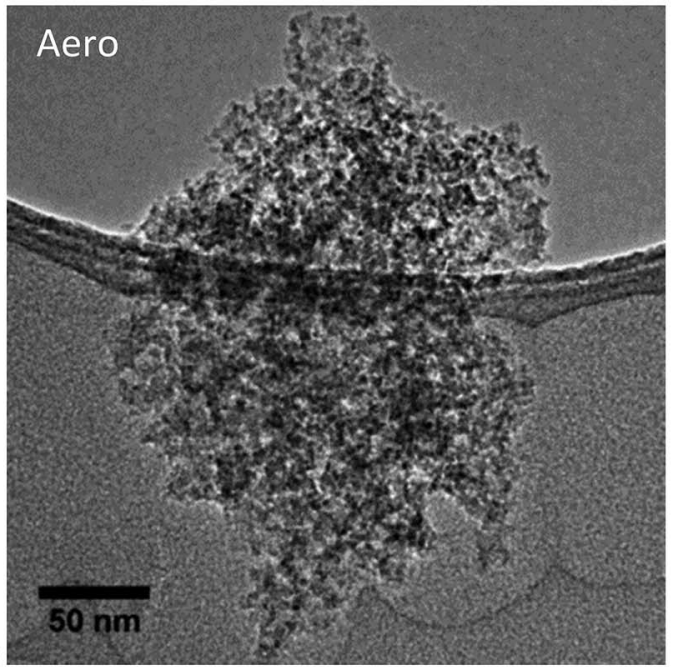

b)

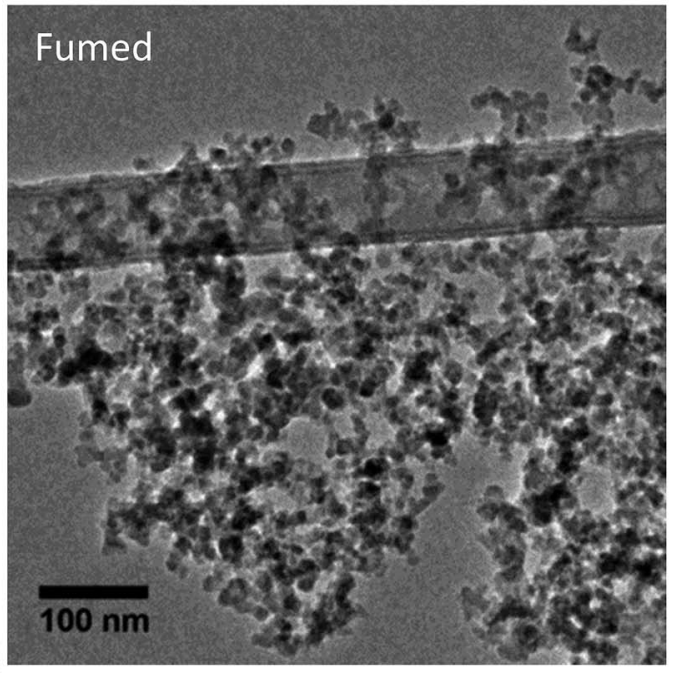

c)

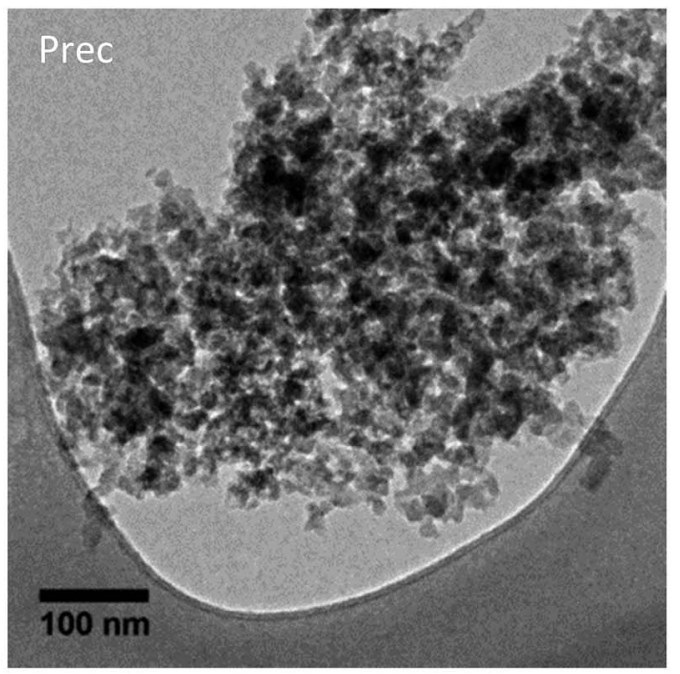

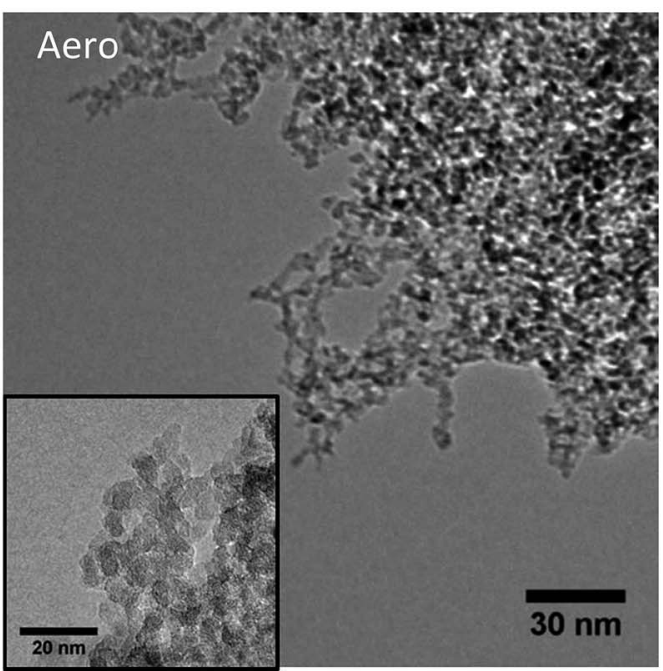
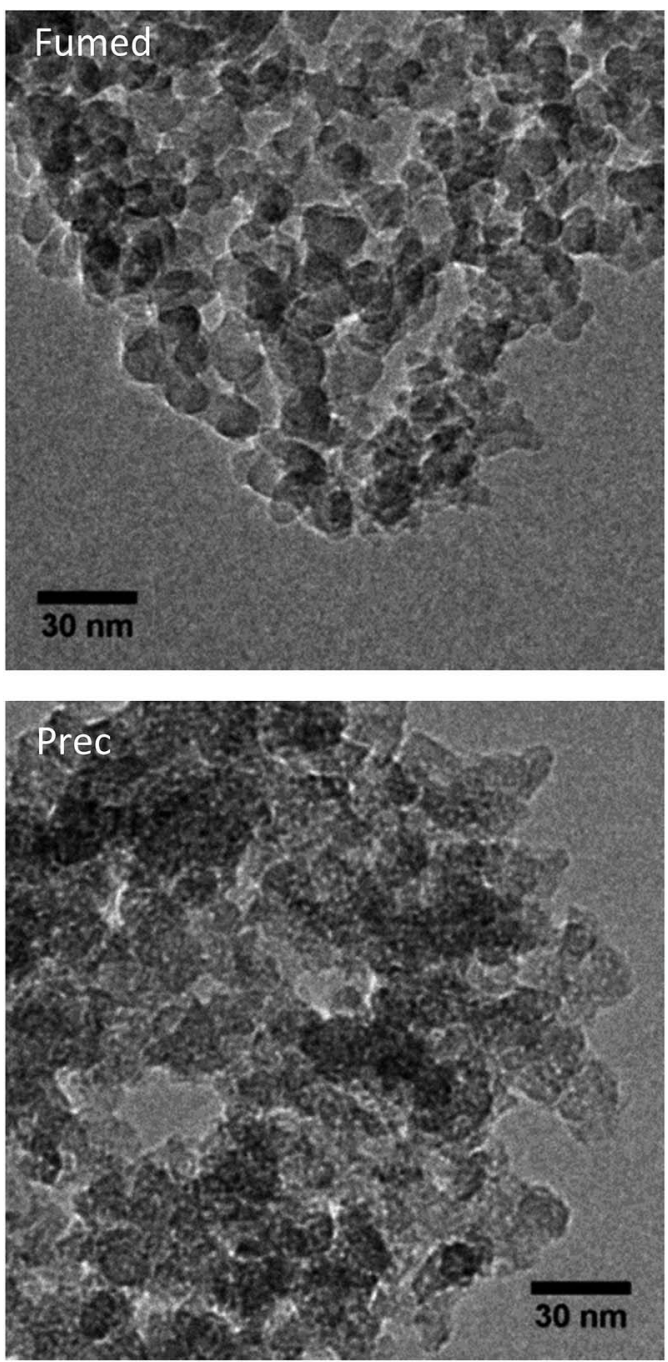

Fig. 1 TEM bright field images at different magnifications: (a) Aero sample, the insert in the right image shows the shape of an Aero nanorod, high resolution images are difficult to obtain due to the beam sensitivity of the samples; (b) Fumed sample and (c) Prec sample. Aggregate morphologies are specific for each sample. The projections gave an initial insight into nanorod and pores sizes are increasing from the Aero sample to Prec sample. 
a)

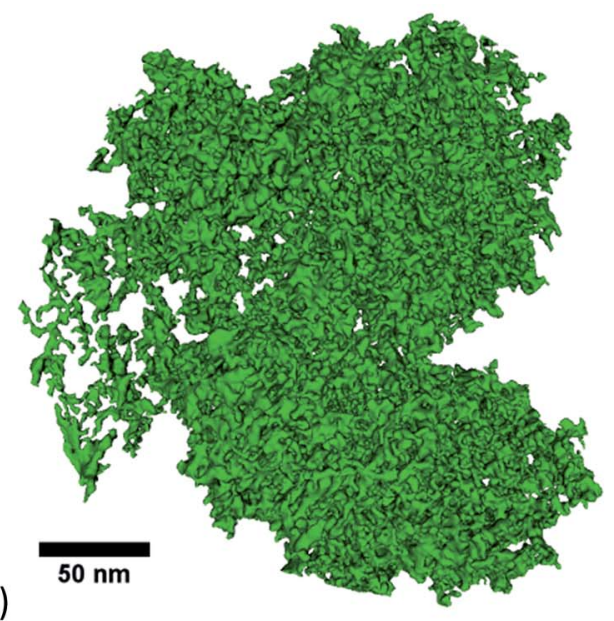

c)

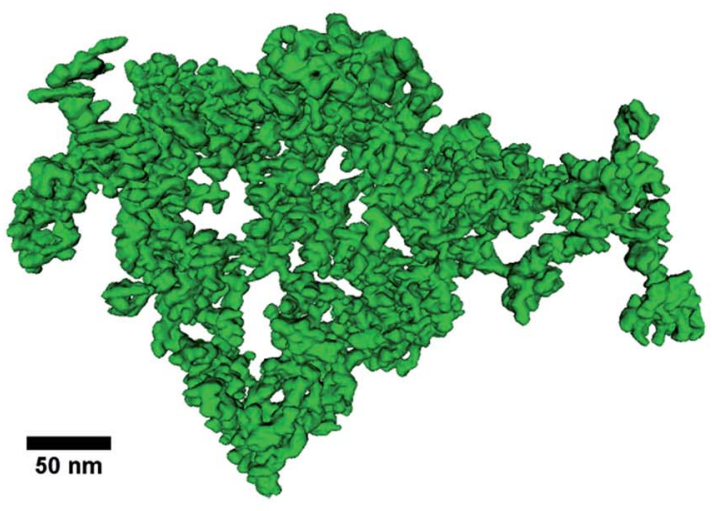

b)

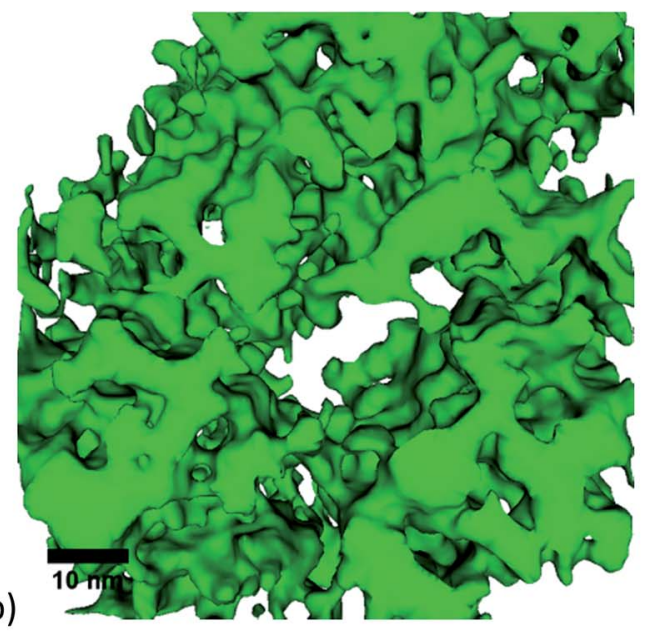

d)

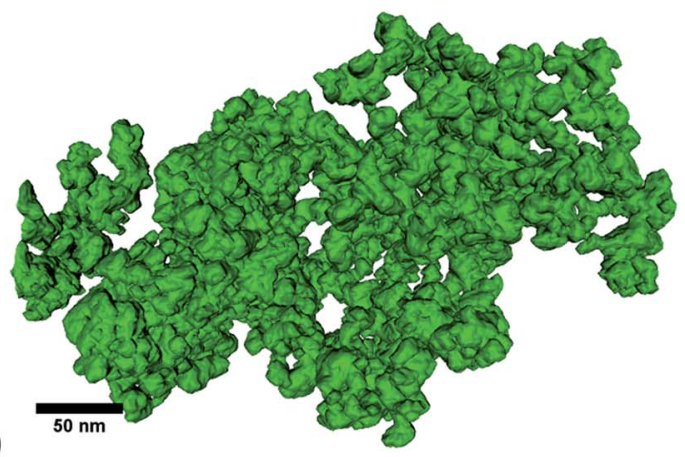

e)

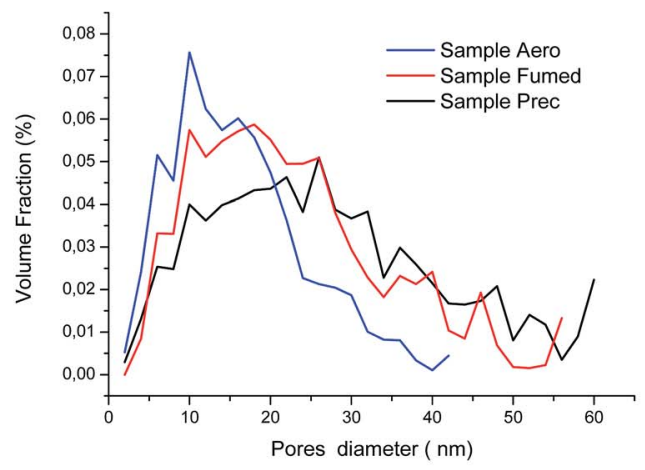

Fig. 2 (a) Three dimensional models of the Aero sample; (b) a volume extracted from the center of the sample at higher magnification, showing the two ends of pore distribution: small $(<7 \mathrm{~nm})$ pores formed between the nanorods like a lattice. The lattices build hollow spheroidal aggregates that include large pores $(>10 \mathrm{~nm}$ ); (c) three dimensional model of the Fumed sample; (d) three dimensional model of the Prec sample; (e) computed pore size distributions obtained by AET analyses. The pore size distribution is increasing with the size of the silica grains from the Aero sample to the Fumed sample and the Prec sample.

Table 3 gives several parameters measured from AET. From a general point of view, the porosity increases with silica particle size, which reflects an increase of the total pore volume.

The pore tortuosity, defined as the ratio between the path in the tortuous pores and the length of a straight segment connecting the pore extremities, was calculated as a three dimensional distance average. This average included both small scale connections (six neighboring pores are considered) and medium scale connections (twenty six neighboring pores are considered). ${ }^{46}$ It was found to be almost constant.

However, the porous network for the Aero sample was the only one composed of an extremely large number of pores, as can be observed in ESI S5, $\dagger$ where the skeletons of the porous networks are modeled. For these models, each pore is 
Table 3 3D quantifications provided by AET: silica particle size of the aerogel sample given by length $(L)$ and width $(W)$, particle aspect ratio $(L / W$, pore size distribution for small pores, big pores, average diameter, porosity proportion, pores tortuosity and the number of pores connection. The last column also shows the computed mesoporous gas conductivity using the length of pores skeleton distribution

\begin{tabular}{|c|c|c|c|c|c|c|c|c|c|c|}
\hline \multirow{2}{*}{ Samples } & \multicolumn{3}{|c|}{ Particles } & \multicolumn{6}{|l|}{ Pore } & \multirow{2}{*}{$\begin{array}{l}\text { Gas conductivity } \\
\left(\mathrm{mW} \mathrm{m}^{-1} \mathrm{~K}^{-1}\right)\end{array}$} \\
\hline & \multicolumn{2}{|l|}{ Size } & $\frac{\text { Aspect ratio }}{(L / W)}$ & \multicolumn{3}{|l|}{ Size } & Porosity (\%) & Tortuosity & $\begin{array}{l}\text { Connections } \mathrm{Nb} \\
\left(\mathrm{N} / 10^{3} \mathrm{~nm}^{3}\right)\end{array}$ & \\
\hline Aero & 5 & 3 & 1.7 & 3 & 10 & 30 & 50 & 1.13 & 1.74 & 2.4 \\
\hline Fumed & 20 & 10 & 2.0 & 7 & 20 & 45 & 63 & 1.10 & 1.14 & 3.2 \\
\hline
\end{tabular}

represented by its center and each connection by a segment. The decrease of the pores density with the increase in pore size due to the increase of the silica particles can be clearly observed in ESI S5. $\uparrow$ Indeed, the larger number of big pores within the aggregate plus the larger number of big pores created at a larger scale between the aggregate certainly induces higher gas mobility inside the material despite the decrease in the number of connections between pores (Table 3). The gas conductivity computation (ESI S6 $\dagger^{\circ}$ ) was performed using as input the pores length connection showed as the pores skeleton in ESI S5. $\dagger$ It was confirmed that $1.3 \mathrm{~mW} \mathrm{~m} \mathrm{~m}^{-1} \mathrm{~K}^{-1}$, i.e. one third of the gas conductivity, can be gained with an adequate powder providing pore of smaller size as possible. As far as super-insulating materials at atmospheric pressure are concerned, the Aero sample was the most suitable native silica-based material, as it exhibited the smallest and narrowest distribution, and therefore the lowest thermal conductivity. In fact, the lowest thermal conductivity was measured for the sample whose nanorods and pores were of equal size, the smallest and shortest pore distribution, low skeleton density and, last but not least, aggregates favoring packing (Aero sample). Such knowledge on the nanostructure of the raw materials implied in superinsulation is of great importance, especially when upscaling to characterization of superinsulation product or systems. Electronic tomography results merged with X-ray tomography ones would ensure the $3 \mathrm{D}$ qualification of porous network at complementary scales.

\section{Conclusions}

This paper dealt with the quantification of the porous volume of silica nanostructures using Electron Tomography performed in advanced mode backed by analysis performed using classical bulk techniques such as $\mathrm{N}_{2}$ physisorption and $\mathrm{Hg}$ porosimetry. Three types of commercial nanostructured silica, under development for the thermal insulation market and obtained by three different synthesis methods, were studied. It was demonstrated that 3D images yield a much finer description of the microstructure compared to global measurements. In particular the size distribution of porous and solid phases could be measured. It was observed that pore size and porous volume increased with silica particle size. The sol-gel sample exhibited smaller silica particles forming very small pores, equal in size to the particles, and small spherical shaped aggregates, whereas the pyrogenic silica had bigger particles and pore sizes and polyhedral branched aggregates. Finally, the precipitated silica studied had the biggest silica particles and the widest pore distribution. Moreover, the pore density in number was found to decrease with increasing pore sizes, whereas the tortuosity measured was almost constant. The smaller native mesopores in the aerogel sample favored low thermal conductivity.

From a more general point of view, advanced electron tomography is a very powerful tool which permits the quantification of beam sensitive nanostructured materials. It was demonstrated that AET can be used for imaging the nanostructures of raw silica materials.

\section{Acknowledgements}

The authors are grateful to Prof. O. Ersen and Dr G. Melinte for providing access to the JEOL $2100 \mathrm{~F}$ microscope through the METSA program as well as to Miss Laetitia Dewolf for her involvement in formulating and characterizing the samples. The authors would also like to thank the CLYM infrastructure for providing access to the JEOL 2010F microscope. Lastly, we thank the French Agency for Environment and Energy Management (ADEME), and to the METSA network for their financial support.

\section{Notes and references}

1 P. M. Cox, R. Betts, C. D. Jones, S. Spall and I. J. Totterdell, Nature, 2000, 408, 184-187.

2 European Commission, Commun. from Comm. to Eur. Parliam. Counc. Eur. Econ. Soc. Comm. Comm. Reg, 2010, $\operatorname{COM}(2010), 1-13$.

3 S. Chu and A. Majumdar, Nature, 2012, 488, 294-303.

4 P. Tuominen, K. Klobut, A. Tolman, A. Adjei and M. De BestWaldhober, Energ. Build., 2012, 51, 48-55.

5 J. C. H. Wong, H. Kaymak, S. Brunner and M. M. Koebel, Microporous Mesoporous Mater., 2014, 183, 23-29.

6 E. H. Kennard, Kinetic theroy of gases, McGraw-Hil, New york and London, 1938.

7 O. J. Lee, K. H. Lee, T. Jin Yim, S. Young Kim and K. P. Yoo, J. Non-Cryst. Solids, 2002, 298, 287-292.

8 M. Bouquerel, T. Duforestel, D. Baillis and G. Rusaouen, Energ. Build., 2012, 54, 320-336.

9 R. Baetens, B. P. Jelle and A. Gustavsen, Energ. Build., 2011, 43, 761-769. 
10 H. Katzer and J. Weis, in Organosilicon Chemistry Set: From Molecules to Materials, Wiley-VCH, Weinheim, Germany, 2005, pp. 682-690.

11 A. C. Pierre and G. M. Pajonk, Chem. Rev., 2002, 102, 42434265.

12 A. Du, B. Zhou, Z. Zhang and J. Shen, Materials, 2013, 6, 941968.

13 R. K. Iler, The Chemistry of silica: Solubility, Polymerization, Colloid and Surface Properties and Biochemistry of Silica, Wiley, 1979.

14 K. Quarch, E. Durand, C. Schilde, a. Kwade and M. Kind, Chem. Eng. Res. Des., 2010, 88, 1639-1647.

15 B. Morel, L. Autissier, D. Autissier, D. Lemordant, B. Yrieix and D. Quenard, Powder Technol., 2009, 190, 225-229.

16 P. B. Sarawade, J. K. Kim, A. Hilonga, D. V. Quang, S. J. Jeon and H. T. Kim, J. Non-Cryst. Solids, 2011, 357, 2156-2162.

17 P. B. Sarawade, G. N. Shao, D. V. Quang and H. T. Kim, Appl. Surf. Sci., 2013, 287, 84-90.

18 G. M. Pajonk, A. Venkateswara Rao, N. N. Parvathy and E. Elaloui, J. Mater. Sci., 1996, 31, 5683-5689.

19 S. S. Kistler, J. Phys. Chem., 1932, 36, 52-64.

20 P. H. Debecker, D. P. Hulea and V. Mutin, Appl. Catal., A, 2013, 451, 192-206.

21 G. Reichenauer, U. Heinemann and H. P. Ebert, Colloids Surf., A, 2007, 300, 204-210.

22 S. N. Rigby, S. P. Fletcher and R. S. Riley, Chem. Eng. Sci., 2004, 59, 41-51.

23 F. Despetis, N. Bengourna, B. Lartigue, S. Spagnol and N. Olivi-Tran, J. Non-Cryst. Solids, 2012, 358, 1180-1184.

24 B. Fu, H. Luo, F. Wang, G. Churu, K. T. Chu, J. C. Hanan, C. Sotiriou-Leventis, N. Leventis and H. Lu, J. Non-Cryst. Solids, 2011, 357, 2063-2074.

25 A. Neugebauer, K. Chen, A. Tang, A. Allgeier, L. R. Glicksman and L. J. Gibson, Energ. Build., 2014, 79, 47-57.

26 A. Perret, G. Foray, L. Roiban, K. Masenelli-Varlot, E. Maire, J. Adrien and B. Yrieix, in 2nd Int. Congress on 3D Materials Science, ed. John Wiley \& Sons, John Wiley \& Sons, 2014, pp. 29-34.

27 P. A. Midgley and M. Weyland, Ultramicroscopy, 2003, 96, 413-431.

28 H. Friedrich, P. E. de Jongh, A. J. Verkleij and K. P. de Jong, Chem. Rev., 2009, 109, 1613-1629.

29 J. Zečević, K. P. de Jong and P. E. de Jongh, Curr. Opin. Solid State Mater. Sci., 2013, 17, 115-125.
30 D. Georgescu, L. Roiban, O. Ersen, D. Ihiawakrim, L. Baia and S. Simon, RSC Adv., 2012, 2, 5358-5369.

31 W. E. Zukoki and C. F. Zukoski, Langmuir, 2004, 20, 1119111200.

32 S. Brunauer, P. H. Emmett and E. Teller, J. Am. Chem. Soc., 1938, 60, 309-319.

33 P. P. Barrett, E. P. Joyner and L. G. Halenda, J. Am. Chem. Soc., 1951, 73, 373-380.

34 R. Pirard, C. Alié and J. P. Pirard, Powder Technol., 2002, 128, 242.

35 E. Guerin, P. Tchoreloff, B. Leclerc, D. Tanguy, M. Deleuil and G. Couarraze, Int. J. Pharm., 1999, 189, 91-103.

36 N. E. 725-9, Technical advanced ceramic- caracterisation for powder ceramic - Part 9: bulk density measurement, 2005.

37 M. H. W. Saxton and W. Baumeister, Ultramicroscopy, 1984, 13, 57-70.

38 J. R. Kremer, D. N. Mastronarde and J. R. Mc Intosh, J. Struct. Biol., 1996, 116, 71-76.

39 R. Gordon, R. Bender and G. T. Herman, J. Theor. Biol., 1970, 29, 471-481.

40 C. Messaoudi, T. Boudier, C. O. S. Sorzano and S. Marco, BMC Bioinf., 2007, 8, 288.

41 M. D. Abramoff, P. J. Magalhaes and S. J. Ram, Biophotonics International, 2004, 11, 36-42.

42 A. Fedorov, R. Beichel, J. Kalpathy-Cramer, J. Finet, J.-C. Fillion-Robin, S. Pujol, C. Bauer, D. Jennings, F. Fennessy, M. Sonka, J. Buatti, S. R. Aylward, J. V. Miller, S. Pieper and R. Kikinis, Magn. Reson. Imaging, 2012, 30, 1323-1341.

43 E. F. Pettersen, T. D. Goddard, C. C. Huang, G. S. Couch, D. M. Greenblatt, E. C. Meng and T. E. Ferrin, J. Comput. Chem., 2004, 25, 1605-1612.

44 M. Erb, H. Simmler, S. Brunner, U. Heinemann, H. Schwab, K. Kumaran, P. Mukhopad-hyaya, D. Quénard, H. Sallée, K. Noller, E. Kükükpinar Niarchos, C. tramm, M. Tenpierik and H. Cauberg, Vacuum Insulation Panels. Study on VIPcomponents and panels for service life prediction of VIP in building applications (Subtask A), Technical Report, IEA/ ECBCS Annex 39 HiPTI-project High Performance Thermal Insulation for Buildings and Building Systems, 2005.

45 L. J. S. Huan He, Z. Guo, P. Stroeven and M. Stroeven, Mater. Charact., 2009, 60, 1082-1087.

46 Y. C. K. Chen-Wiegart, R. Demike, C. Erdonmez, K. Thornton, S. a. Barnett and J. Wang, J. Power Sources, 2014, 249, 349-356. 